\title{
Optimisation of the Maillard reaction of bovine gelatine-xylose model using response surface methodology
}

\author{
${ }^{1,4}$ Ismarti, I., ${ }^{2,3}$ Triyana, K., ${ }^{1}$ Fadzilah, N.A., ${ }^{1}$ Salleh, H.M. and ${ }^{1,{ }^{*}}$ Nordin, N.F.H. \\ ${ }^{1}$ International Institute for Halal Research and Training, International Islamic University Malaysia, Jln. \\ Gombak 53100 Selangor Darul Ehsan, Malaysia \\ ${ }^{2}$ Physics Department, Universitas Gadjah Mada, Yogyakarta, Sekip Utara, BLS 21, Yogyakarta, Indonesia \\ ${ }^{3}$ Institute of Halal Industry and System (IHIS) Universitas Gadjah Mada, Jl. Kaliurang Km. 4, Sekip Utara, \\ Yogyakarta, Indonesia \\ ${ }^{4}$ Department of Mathematics Education, Faculty Teaching Training and Education, Universitas Riau \\ Kepulauan, Jl. Batuaji Baru No.99, Batam, Indonesia
}

\author{
Article history: \\ Received: 19 August 2019 \\ Received in revised form: 23 \\ October 2019 \\ Accepted: 3 November 2019 \\ Available Online: 10 \\ February 2020
}

\section{Keywords:}

Central composite design,

Maillard reaction,

Browning intensity,

Melanoidins

DOI:

https://doi.org/10.26656/fr.2017.4(S1).S13

\begin{abstract}
The Maillard reaction is known as an amino-carbonyl reaction or non-enzymatic browning reaction which has an essential role in food processing to improve the appearance, taste and functional properties of food. In halal authentication, results could be used to differentiate the sources of gelatine based on the colour and flavour. Since many factors can influence the reaction, it is important to study and optimize the Maillard reaction in a gelatine model system using response surface method, applied to optimize the processing of bovine gelatine-xylose to improve the Maillard reaction products. In this study, the effects of initial $\mathrm{pH}$, temperature, and heating time to browning intensity of melanoidin were evaluated. The increasing of initial $\mathrm{pH}$, temperature and heating time were associated with an enhanced browning intensity of Maillard reaction products. This study demonstrated that the coefficient of determination 0.8429 reveals the response surface reduced linear model is an adequate model for browning intensity of Maillard reaction of the bovine gelatine-xylose system. For a system with $5 \%$ of gelatine solution and $0.75 \mathrm{~g}$ of xylose, the optimum condition for the browning process obtained was initial of $\mathrm{pH} 10.92$, temperature of $140^{\circ} \mathrm{C}$ and heating time of 37.28 mins. The predicted results at optimum conditions coincided well with the experimental value with the relative error of less than $5 \%$.
\end{abstract}

\section{Introduction}

The Maillard reaction is known as a non-enzymatic browning reaction. It refers to a chemical reaction that occurs between the carbonyl groups of reducing sugars and the amino group of amino acids, peptides or protein (Wang et al., 2011). This reaction has played an important role in improving the appearance and taste of food since the Maillard reaction is related to aroma, taste and colour. Also, a wide range of reaction products is formed during the Maillard reaction has significant importance for the nutritive value (Martins et al., 2001). It was reported that the Maillard reaction products (MRPs) have antioxidant activity (Chen and Kitts, 2008; Liu et al., 2016), anti-allergenic of protein, antimicrobial activity, probiotic activity and also antihypertensive activity (Wang et al., 2011).

Generally, the Maillard reaction is divided into three stages. The first stage is the initial stage, which starts with sugar-amine condensation followed with Amadori rearrangement if the sugar is aldose and Heyns rearrangement if the sugar is ketose. The products in the initial stage are colourless without absorption in the ultraviolet spectrum (about $280 \mathrm{~nm}$ ). The second stage is the intermediate stage, which includes sugar degradation, sugar fragmentation and amino acid degradation (Strecker degradation). In this stage, the colourless or yellow product with strong absorption in the ultraviolet spectrum is formed. In the final stage, aldol condensation, aldehyde-amine condensation, and formation of heterocyclic nitrogen compounds are involved. Products in this stage are highly coloured with a compound called melanoidin (Nursten, 2005).

The colour formation is the primary characteristic of the Maillard reaction which can be readily at the absorbance in the visible region of between 360 and 420 
$\mathrm{nm}$. The typical shape of the absorption curve of soluble crude Maillard reaction products is featureless and asymptotic where the absorption is strong at below 400 $\mathrm{nm}$ (Nursten, 2005; Rizzi, 2011), but gradually decrease at the higher wavelengths (Nursten, 2005). According to Rizzi (2011), the absence of discrete absorption maxima in the visible region has been interpreted as the result of a polymerization process.

Melanoidins are polymers with a high molecular weight of about $1500 \mathrm{kDa}$ which usually contains 3-4\% nitrogen (Nursten, 2005), and some residual protein (Rizzi, 2011). Food melanoidins are anionic compounds predominantly responsible for the characteristic brown colour of food such as coffee, cocoa, bread, malt and honey (Wang et al., 2011). The complex array of melanoidins produced in the Maillard reaction is strongly dependent on the types of food, as well as the technological conditions of the reactions such as treating temperature and time, $\mathrm{pH}$, solvent, and the compositions of the amino acids and reducing sugar (Van Boekel, 2006; Jaeger et al., 2010; Wang et al., 2011). According to Kwak and Lim, 2004), the colour intensities of MRPs containing basic amino acids was reported greater than that of acidic amino acids, while nonpolar amino acidic have intermediate colour intensities. In addition, browning was accelerated by the presence of metal ions $\left(\mathrm{Fe}^{2+}\right.$ and $\left.\mathrm{Cu}^{2+}\right)$ but inhibit by $\mathrm{Na}^{+}$.

Gelatine has been used in a wide range of food products. MRPs of gelatine is one of the special interests in halal authentication since these products allow differentiation of the gelatine based on its origin and sources. The sources of gelatine in the market are mammal gelatine, mainly from porcine and bovine also, little supply from fish. However, the unclear labels of gelatine in the market in terms of their sources raise doubts among Muslim consumers, since the Muslim are prohibited from consumption of porcine derivatives. Study on the Maillard reaction for differentiation of gelatine has been reported by Tan et al., (2012) where the bovine and porcine gelatines were successfully differentiated with UV-spectroscopy. In 2017, Hamizah et al. reported that the presence of $\mathrm{Cu}^{2+}$ in the Maillard reaction of gelatine causes an increased rate of browning. Also, our previous study has successfully established the method for classification of bovine, porcine and fish gelatines based on flavours using an electronic nose. In the study, the Maillard reaction has enhanced the accuracy of the method since it improved the flavour of gelatine.

In this study, optimization of Maillard reaction from the gelatine-xylose model was conducted since it influences sensory characteristics such as colour, aroma and taste possible as use for gelatine authentication.

\section{Materials and methods}

\subsection{Chemicals}

Chemicals used were bovine skin gelatine type B and xylose, purchased from Sigma Aldrich, Germany, sodium hydroxide and hydrochloric acid from Merck, and ultrapure water. All chemicals used were of analytical grade.

\subsection{Screening of variables influence the browning intensity}

The first step in the design of the experiment is screening and choosing the process parameters, and the response variables for optimization using one factor at-atime (OFAT) method. According to previous experimental findings, the most influential factors of Maillard reaction are gelatine concentration, xylose concentration, initial $\mathrm{pH}$, reaction temperature, and heating time. The browning intensity indicates the MRPs formation and was measured at an absorbance of 360 $\mathrm{nm}$.

\subsubsection{Gelatine solution concentration}

A series of gelatine solution $(5,10$ and $15 \%(\mathrm{w} / \mathrm{v}))$ were prepared by dissolving standard bovine gelatine in $100 \mathrm{~mL}$ ultrapure water. The mixtures were homogenized at $60^{\circ} \mathrm{C}$ using a hotplate stirrer. The solution was cooled at room temperature for further step. The $\mathrm{pH}$ of the solution was determined with a $\mathrm{pH}$ meter.

\subsubsection{Xylose concentration}

About $5 \mathrm{~mL}$ of gelatine solution was put into a screw -sealed tube. A variation weight of xylose $(0.25 \mathrm{~g}, 0.50$ $\mathrm{g}, 0.75 \mathrm{~g}$, and $1.00 \mathrm{~g}$ ) was added into the solution. The tube was tightly capped, homogenized and heated in a water bath at $90^{\circ} \mathrm{C}$ for 60 mins. After heating, the samples were immediately placed in an ice bath to stop the further reaction. The browning intensity was determined following the method of Liu et al. (2016). Appropriate dilution (10-fold) of the MRPs was made, and the absorbance was measured at $360 \mathrm{~nm}$ using a USB4000 UV-Visible Spectrophotometer with Ocean View software 1.5.0 version. All samples were prepared in duplicates.

\subsubsection{Initial $p H$}

In order to evaluate the effects of the initial $\mathrm{pH}$, a series of $5 \%$ gelatine solution were prepared at different $\mathrm{pH}$ of $4,6,8,10$ and 12 using $1 \mathrm{M} \mathrm{HCl}$ or $1 \mathrm{M} \mathrm{NaOH}$. About $5 \mathrm{~mL}$ of the gelatine solution was mixed with 0.75 $\mathrm{g}$ of xylose in a screw-sealed tube, homogenized and 
heated at $90^{\circ} \mathrm{C}$ for 60 mins. The browning intensity was measured as in Section 2.2.2.

\subsubsection{Reaction temperature}

About $5 \mathrm{~mL}$ of gelatine solution $(5 \% \mathrm{w} / \mathrm{v})$ from the optimum initial $\mathrm{pH}$ was prepared with $0.75 \mathrm{~g}$ of xylose. The mixture was heated at different temperatures $(70,80$, $90,100,110,120,130,140$ and $150^{\circ} \mathrm{C}$ ) for 60 mins to evaluate the effect of temperature on browning intensity. The browning intensity was measured as in Section 2.2.2.

\subsubsection{Heating time}

About $5 \mathrm{~mL}$ of gelatine solution $(5 \% \mathrm{w} / \mathrm{v})$ from the optimum temperature was prepared with $0.75 \mathrm{~g}$ of xylose. The mixture was heated at $140^{\circ} \mathrm{C}$ with the variation of heating time $(0,15,30,45,60$ and 75 minutes) to evaluate the effect of heating time on browning intensity. The browning intensity was measured as in Section 2.2.2.

\subsubsection{Statistical analysis}

Effect of variables on the browning intensity as the representation of Maillard product was analyzed using one-factor-at-a time (OFAT) method. All of the measurements on each sample were carried out in duplicate. The results were shown in mean \pm standard deviation (SD) and subjected to analysis of variance (ANOVA) using Microsoft Excel 2010. Mean values were compared using Tukey's test at $\mathrm{P}<0.05$.

\subsection{Optimization of Maillard reaction model}

\subsubsection{Design of experiment}

In order to evaluate interactions between initial $\mathrm{pH}$, temperature and heating time, Response Surface Methodology (RSM) with Central Composite Design (CCD) was used in designing the experiment. The design was constructed using Design Expert Version 6.0.8 leading to 17 sets of experiments, allowing each experimental response to be optimized. The experimental design of the coded $(\mathrm{X})$ and actual (initial $\mathrm{pH}$, reaction temperature, and heating time) level of variables are shown in Table 1. Each independent variable had coded levels of -1 (low level) and +1 (high level). The responses functions $\mathrm{Y}$ was related to coded variables $\left(\mathrm{X}_{\mathrm{i}}\right.$, $\mathrm{i}=1,2,3,4)$ by the following second-order polynomial equation (Zhang et al., 2016):

$$
Y=b_{0}+\sum_{i=1}^{4} b_{i} X_{i}+\sum_{i=1}^{4} b_{i i} X_{i}^{2}+\sum_{i=1}^{3} \sum_{j=i+1}^{4} b_{i j} X_{i} X_{j}
$$

Where $Y$ represent browning intensity; $b_{0}$ represent constant; $b_{i}$ represents the regression coefficient for linear effect; $b_{i i}$ represents the quadratic coefficient, and $b_{i j}$ represents the interaction coefficient.
The Maillard reaction model system was prepared based on results obtained from Section 2.2. The system consisted of about $5 \mathrm{~mL}$ of gelatine solution $(5 \% \mathrm{w} / \mathrm{v})$ and $0.75 \mathrm{~g}$ of xylose. The mixture was put into screwsealed tubes, tightly capped and heated in a water bath according to the experimental design in Table 1 in duplicates. After heating, the samples were immediately placed in an ice bath to stop further reaction. The obtained MRPs samples were determined using UV Visible spectrophotometer at $360 \mathrm{~nm}$. The average values were recorded as the response.

Table 1. Design of experiment using Design Expert version 6.0.8.

\begin{tabular}{cccc}
\hline \multirow{2}{*}{ Level code } & \multirow{2}{*}{ Variable } & \multicolumn{2}{c}{ Variable level } \\
\cline { 3 - 4 } & Initial $\mathrm{pH}$ & -1 & 1 \\
\hline $\mathrm{X}_{1}$ & Temperature $\left({ }^{\circ} \mathrm{C}\right)$ & 120 & 12 \\
$\mathrm{X}_{2}$ & Heating time $(\mathrm{min})$ & 30 & 45 \\
$\mathrm{X}_{3}$ & &
\end{tabular}

\subsubsection{Statistical analysis}

Analysis of variance (ANOVA) was performed using Design Expert Version 6.0.8 where ANOVA tables were generated, and the effect and regression coefficient of individual linear, quadratic and interaction terms were determined. The statistical significance of the regression coefficient was determined by using F-test and lack of fit test, while the applicability of the model was checked with significance coefficients of determination $\left(\mathrm{R}^{2}\right)$ values. The optimum processing conditions were obtained by using numerical analysis based on the criterion of desirability.

\subsection{Validation model}

Validation model was performed based on the conditions recommended by the Design-Expert software. The measurement was performed in triplicate. The mean $\pm \mathrm{SD}$ of results from the experiment were compared with the predictive value from the model to get the percentage of relative error by using the Equation (2).

$$
\text { Relative error }=\left|\frac{\text { predictive value-actual value }}{\text { predictive value }}\right| \times 100 \%
$$

\section{Results and discussion}

Standard bovine gelatine was used in this study. Xylose was used in this model because of its high reactivity and relatively lower cost compared to other hexoses. As many factors can influence the Maillard reaction, CCD using RSM was applied to determine the best conditions. Response surface methodology is a collection of statistical and mathematical techniques useful for the improvement and optimization of complex processes. The main advantage of RSM is its ability to reduce the number of experimental trials needs to 
evaluate multiple parameters and their interaction to provide sufficient information for statistically acceptable results (Gu et al., 2009; Burin et al., 2013).

\subsection{Effect of variables measurement on browning intensity}

\subsubsection{Gelatine solution concentration}

In this study, gelatine solution with variation in concentrations 5,10 and $15 \%(\mathrm{w} / \mathrm{v})$ was used. The $\mathrm{pH}$ of the gelatine solutions at different concentrations is shown in Table 2. Statistical analysis using ANOVA for OFAT method indicated that the calculated $F$ value (0.64) was less than tabulated F value (9.55) and P-value higher than 0.05 . It means that there is no significant difference between the $\mathrm{pH}$ of gelatine solution with a variation of concentration before reaction. However, gelatine solution with $10 \%(\mathrm{w} / \mathrm{v})$ and $15 \%(\mathrm{w} / \mathrm{v})$ concentrations are not suitable for use in the experiment since the solution thickness at room temperature. Based on this fact, this study used $5 \%(\mathrm{w} / \mathrm{v})$ concentration of gelatine for further experiment.

Table 2. $\mathrm{pH}$ of gelatine solution at variated concentrations

\begin{tabular}{cc}
\hline Gelatine concentration $(\%)$ & $\mathrm{pH}$ \\
\hline 5 & $4.64 \pm 0.01^{\mathrm{a}}$ \\
10 & $4.67 \pm 0.04^{\mathrm{a}}$ \\
15 & $4.66 \pm 0.01^{\mathrm{a}}$ \\
\hline
\end{tabular}

Mean \pm SD $(n=3)$. Different superscripts within the same column indicate the significant difference $(\mathrm{P}<0.05)$.

\subsubsection{Xylose concentration}

Four variations of weights of xylose $(0.25 \mathrm{~g}, 0.5 \mathrm{~g}$, $0.75 \mathrm{~g}$ and $1.00 \mathrm{~g}$ ) were used to evaluate the effect of xylose on the browning intensity. The results of browning intensity were recorded at the absorbance of $360 \mathrm{~nm}$ wavelength. As shown in Table 3, there is increasing in browning intensity with the increasing of xylose weight. Statistical analysis using ANOVA single factors obtained for the calculated $F$ value (73.95) was higher than the tabulated $F$ value (6.59) at alpha 0.05. It means that there is a significant difference for browning intensity with the difference of xylose weight.

Table 3. Browning intensity of Maillard products at variation xylose weight

\begin{tabular}{cc}
\hline Xylose $(\mathrm{g})$ & $\mathrm{A}_{360}$ \\
\hline 0.25 & $1.08 \pm 0.07^{\mathrm{a}}$ \\
0.5 & $1.74 \pm 0.13^{\mathrm{b}}$ \\
0.75 & $2.09 \pm 0.01^{\mathrm{c}}$ \\
1 & $2.13 \pm 0.06^{\mathrm{c}}$ \\
\hline
\end{tabular}

$\mathrm{A}_{360}=$ Absorbance at the wavelength of $360 \mathrm{~nm}$. Different superscripts within the same column indicate the significant difference $(\mathrm{P}<0.05)$.

Further analysis using the Tukey's test obtained HSD $(0.05,3,4)=0.28$. This value was then compared with the different means of each group. The results of Tukey's test in Table 3 shows that there is a significant difference in browning intensities for variations of xylose except for $0.75 \mathrm{~g}$ and $1.00 \mathrm{~g}$ of xylose.

\subsubsection{Initial $p H$}

To evaluate the effect of initial $\mathrm{pH}, 5 \%$ of gelatine solution mixed with $0.75 \mathrm{~g}$ of xylose was used. The browning intensity was determined at the absorbance of $360 \mathrm{~nm}$ after heating at $90^{\circ} \mathrm{C}$ for 60 mins, as shown in Table 4. From the table, it is clear that the browning in the Maillard products increased moderately with the increase in initial $\mathrm{pH}$ within the range of 4 to 12 . Statistical analysis using ANOVA indicated that there is a significant difference in browning intensities as affected by initial $\mathrm{pH}$, as shown by the $\mathrm{F}$ value calculated (67.24) higher than $F$ value tabulated (5.19) at alpha 0.05 . However, the Tukey's test showed that there is no significant difference in browning intensity for Maillard products with initial $\mathrm{pH}$ of 6,8 and 10 .

Table 4. Effect of initial $\mathrm{pH}$ on browning intensity

\begin{tabular}{cc}
\hline Initial $\mathrm{pH}$ & $\mathrm{A}_{360}$ \\
\hline 4 & $0.09 \pm 0.03^{\mathrm{a}}$ \\
6 & $0.57 \pm 0.05^{\mathrm{b}}$ \\
8 & $0.57 \pm 0.08^{\mathrm{b}}$ \\
10 & $0.56 \pm 0.06^{\mathrm{b}}$ \\
12 & $0.98 \pm 0.04^{\mathrm{c}}$
\end{tabular}

Different superscripts within the same column indicate the significant difference $(\mathrm{P}<0.05)$.

High initial $\mathrm{pH}$ is therefore beneficial to produce Maillard products from bovine gelatine-xylose models as the Maillard reaction is catalyzed in alkaline condition (Nursten, 2005; Gu et al., 2009). Based on the

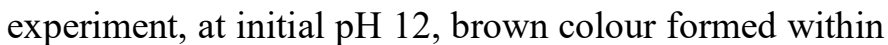
the first 15 mins of reaction. However, for initial $\mathrm{pH} 8$ 10, the brown colour formed after 30 minutes while for $\mathrm{pH} 4$ it formed after 45 mins of heating time. The presence of amine or alkaline condition will increase the reaction rate since base or amine can act as a catalyst for Maillard reaction. At the final stage, the $\mathrm{pH}$ of Maillard reaction drops from 4.95-4.65. The final stage of the Maillard reaction involves aldol condensation. In this step, aldehydes from the intermediate stage can react with each other. The presence of amine in the system will increase the reaction rate since the amines are effective catalysts. At the end of the process, aldehydes react readily at low temperatures with amines to give polymeric high molecular mass, coloured products of unknown structures, called melanoidins (Nursten, 2005). According to Ames and Apriyantono (1994), $\mathrm{pH}$ has an important influence on the profile of products formed during the Maillard reaction. 


\subsubsection{Reaction temperature}

For this study, $5 \mathrm{~mL}$ of gelatine solution $(5 \% \mathrm{w} / \mathrm{v})$ at $\mathrm{pH} 12$ (from Section 3.1.3) was mixed with $0.75 \mathrm{~g}$ of xylose and homogenized. The solutions were heated at different temperatures for 30 mins. Effect of temperatures on the browning intensities is shown in Table 5. From the results in Table 5, the brown Maillard products were formed at $70^{\circ} \mathrm{C}$. The browning increased slightly with increasing temperature and reached the maximum at $140^{\circ} \mathrm{C}$. It is therefore clear that the temperature has a significant effect on the browning intensity. It was supported by ANOVA results where the $F$ value calculated (2400.34) higher than $F$ value tabulated (3.23) at alpha 0.05 and P-value $<0.05$. According to Nursten (2005), the browning increased 2-6 times with increasing $10^{\circ} \mathrm{C}$ in temperature. Further analysis using Tukey's test shows it is significantly different between browning intensity in low-temperature group $\left(70-90^{\circ} \mathrm{C}\right)$, middle-temperature group $\left(100-120^{\circ} \mathrm{C}\right)$ and high-temperature group $\left(130-150^{\circ} \mathrm{C}\right)$. However, there is no significant difference in browning intensity within the group for low-temperature and hightemperature groups.

Table 5. Effect of temperature on browning intensity

\begin{tabular}{cc}
\hline Temperature $\left({ }^{\circ} \mathrm{C}\right)$ & $\mathrm{A}_{360}$ \\
\hline 70 & $0.02 \pm 0.01^{\mathrm{a}}$ \\
80 & $0.04 \pm 0.05^{\mathrm{a}}$ \\
90 & $0.04 \pm 0.01^{\mathrm{a}}$ \\
100 & $0.44 \pm 0.04^{\mathrm{b}}$ \\
110 & $1.05 \pm 0.05^{\mathrm{c}}$ \\
120 & $1.50 \pm 0.02^{\mathrm{d}}$ \\
130 & $2.40 \pm 0.00^{\mathrm{e}}$ \\
140 & $2.45 \pm 0.01^{\mathrm{e}}$ \\
150 & $2.42 \pm 0.04^{\mathrm{e}}$ \\
\hline
\end{tabular}

$\mathrm{A}_{360}=$ Absorbance at the wavelength of $360 \mathrm{~nm}$. Different superscripts within the same column indicate the significant differences $(\mathrm{P}<0.05)$.

\subsubsection{Heating time}

The last variable studied that also influenced the browning in Maillard products is heating time. The browning intensity of Maillard product of gelatinexylose system at variation of heating time between 0.96 to 2.90 is as shown in Table 6. It is clear that the browning intensity increased slightly within the first 15 mins of heating time and fluctuated after that. Statistical analysis using ANOVA shows that the $\mathrm{F}$ value calculated (83.80) was higher than F-value tabulated (4.39) at alpha 0.05 and $\mathrm{P}$-value $<0.05$. It means that there is a significant difference in the browning intensity at different heating time.

Further analysis to explore the source of significant difference was done using Tukey's test. From the results obtained, 0 min of heating time showed a significant difference from other heating times. In addition, there was no significant difference in browning intensities at $15,30,45,60$ and 75 mins of heating time.

Table 6. Effect of heating time on browning intensity

\begin{tabular}{cc}
\hline Heating time $(\min )$ & $\mathrm{A}_{360}$ \\
\hline 0 & $0.96 \pm 0.01^{\mathrm{a}}$ \\
15 & $2.79 \pm 0.01^{\mathrm{b}}$ \\
30 & $2.66 \pm 0.11^{\mathrm{b}}$ \\
45 & $2.90 \pm 0.09^{\mathrm{b}}$ \\
60 & $2.81 \pm 0.19^{\mathrm{b}}$ \\
75 & $2.80 \pm 0.16^{\mathrm{b}}$ \\
\hline
\end{tabular}

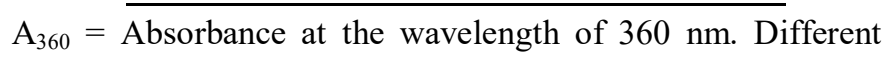
superscripts within the same column indicate the significant differences $(\mathrm{P}<0.05)$.

\subsection{Optimization of Maillard model}

A model equation for the Maillard reaction of the gelatine-xylose system was developed to evaluate the interactions between variables in order to determine the optimum operating condition. Central Composite Design using Design Expert software was used for this purpose. The optimum processing parameters which yielded bovine gelatine-xylose with high melanoidin in the bovine gelatine-xylose system indicated by the high browning intensity detected at $360 \mathrm{~nm}$ were determined. The result of Central Composite Design for browning intensity is given in Table 7 .

Based on the analysis, the polynomial model for browning intensity response was linear. This model was tested for adequacy and goodness of fit by analysis of variance (ANOVA) as shown in Table 8 . The model had F-value of 23.26 implying that the model is significant since the Prob $>$ F values were less than 0.05 and statistically significant at the $95 \%$ confidence level. The model for browning intensity response showed $\mathrm{R}^{2}$ value 0.8429 which means that $84.29 \%$ experiment of the data relevant and $25.71 \%$ of the total variance could not be explained by the model. Based on the statistical model, the adjusted R-square value of 0.8067 indicated $80.67 \%$ of the actual data for browning intensity was covered in the model. However, using this model, predictive Rsquare value of 0.6858 indicated that only $68.58 \%$ of predictive data was covered in the model. Adequate precision value for browning intensity higher than 4 (11.17) revealed that the signal to noise ratio is an adequate signal. Therefore, the browning intensity of Maillard products of gelatine-xylose can be predicted from Equation (3).

Browning intensity $=-0.21635-0.001$ initial $p H+0.0195$ temperature $+5.33 \times$ $10^{-4}$ heating time

As shown in Table 8, only temperature of reaction 
Table 7. Central composite design for the measure of browning intensity.

\begin{tabular}{ccccc}
\hline Run & Initial $\mathrm{pH}$ & Temperature $\left({ }^{\circ} \mathrm{C}\right)$ & Time $(\operatorname{mins})$ & $\mathrm{A}_{360}$ \\
\hline 1 & 10 & 130 & 37.5 & 2.39 \\
2 & 10 & 140 & 30 & 2.54 \\
3 & 12 & 140 & 45 & 2.44 \\
4 & 10 & 120 & 30 & 2.01 \\
5 & 12 & 120 & 30 & 2.02 \\
6 & 10 & 140 & 45 & 2.48 \\
7 & 12 & 120 & 45 & 2.13 \\
8 & 11 & 130 & 37.5 & 2.36 \\
9 & 10 & 120 & 45 & 2.17 \\
10 & 11 & 130 & 37.5 & 2.32 \\
11 & 11 & 140 & 37.5 & 2.43 \\
12 & 12 & 140 & 30 & 2.59 \\
13 & 11 & 120 & 37.5 & 2.2 \\
14 & 12 & 130 & 37.5 & 2.4 \\
15 & 11 & 130 & 30 & 2.36 \\
16 & 11 & 130 & 45 & 2.34 \\
17 & 11 & 130 & 37.5 & 2.39 \\
\hline
\end{tabular}

$\mathrm{A}_{360}=$ Absorbance at the wavelength of $360 \mathrm{~nm}$.

Table 8. ANOVA for response surface linear model

\begin{tabular}{lcccccc}
\hline \multicolumn{1}{c}{ Source } & Sum of Squares & DF & Mean Square & F Value & Prob $>$ F & \\
\hline Model & 0.38042 & 3 & 0.12681 & 23.2555 & $<0.0001$ & significant \\
Initial pH & 0.00001 & 1 & 0.00001 & 0.00183 & 0.9665 & \\
Temperature & 0.38025 & 1 & 0.38025 & 69.73532 & $<0.0001$ & \\
Heating time & 0.00016 & 1 & 0.00016 & 0.02934 & 0.8666 & \\
Residual & 0.07087 & 13 & 0.00545 & & & \\
Lack of Fit & 0.06842 & 11 & 0.00622 & 5.04319 & 0.177 & not significant \\
Pure Error & 0.00247 & 2 & 0.00123 & & & \\
Cor Total & 0.45131 & 16 & & & & \\
\hline
\end{tabular}

has a significant effect on the browning intensity shown by values of "Prob $>$ F" less than 0.05 . In this study, initial $\mathrm{pH}$ and heating time have no significant effect on the browning intensity. The reduced version of the model was performed to improve the model by excluding both insignificant variables. By using the reduced linear model, adjusted R-squared increased by about $2.54 \%$ (from 80.67 to 83.21). However, the predictive data covered in the model increased by about $10 \%$ (from 68.58 to $78.71 \%$ ). Final equation of factors involved in the reduced linear model is as in Equation (4) and statistical analysis of the reduced model is as shown in Table 9.

$$
\text { Browning intensity }=-0.20753+0.0195 \text { temperature }
$$

Figure 1 shows the dependency of browning intensity toward the initial $\mathrm{pH}$ and temperature at a constant heating time. It is clear that at a constant heating time and initial $\mathrm{pH}$, browning intensity increased moderately with increasing temperature. This may also be seen from Figure 1 where that initial $\mathrm{pH}$ in the range of 10-12 has no significant effect on the optimization results. According to Ames and Apriyantono (1994), the rate of Maillard browning increases with $\mathrm{pH}$ over the $\mathrm{pH}$ range 4-8. When the $\mathrm{pH}$ range is extended up to $\mathrm{pH} 12$, the rate of browning in sugar-amino acid model systems shows a maximum at a $\mathrm{pH}$ of about 10 .

Based on the condition suggested by the software (desirability 0.88 ), the optimum conditions for browning

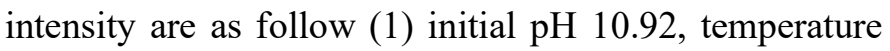
$140^{\circ} \mathrm{C}$, and heating time 37.28 mins; (2) initial $\mathrm{pH} 11.96$, temperature $140^{\circ} \mathrm{C}$, and heating time 32.22 mins. The response calculated from the final set of conditions gave the browning intensity of 2.52 at $360 \mathrm{~nm}$.

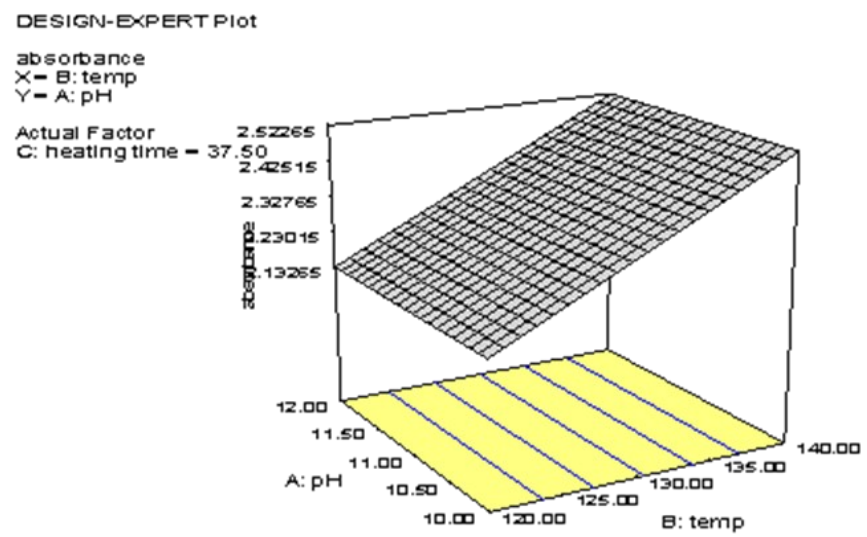

Figure 1. Three-dimensional diagram of the interactive effects between initial $\mathrm{pH}$ and temperature on browning intensity at the constant heating time (37.50 mins) 
Table 9. ANOVA for response surface reduced linear model

\begin{tabular}{lccccccc}
\hline \multicolumn{1}{c}{ Source } & Sum of Squares & DF & Mean Square & F Value & Prob $>$ F & & \\
\hline Model & 0.38025 & 1 & 0.38025 & 80.27133 & 80.27133 & $<0.0001$ & significant \\
Temperature & 0.38025 & 1 & 0.38025 & 80.27133 & 80.27133 & $<0.0001$ & significant \\
Residual & 0.07106 & 15 & 0.00474 & & & & not significant \\
Lack of Fit & 0.06859 & 13 & 0.00528 & 4.27791 & 4.27791 & 0.2052 & \\
Pure Error & 0.00247 & 2 & 0.00123 & & & & \\
Cor Total & 0.45131 & 16 & & & & & \\
\hline
\end{tabular}

Table 10. Result of predicted and actual data at optimum condition for browning intensity

\begin{tabular}{cccccc}
\hline Initial $\mathrm{pH}$ & Temperature $\left({ }^{\circ} \mathrm{C}\right)$ Heating time $(\mathrm{min})$ & $\mathrm{A}_{360}$ predicted & $\mathrm{A}_{360}$ actual & Relative error \\
\hline 10.92 & 140 & 37.28 & 2.52 & $2.64 \pm 0.00$ & $4.68 \%$ \\
11.95 & 140 & 32.22 & 2.52 & $2.67 \pm 0.02$ & $6.07 \%$ \\
\hline
\end{tabular}

$\mathrm{A}_{360}=$ Absorbance at the wavelength of $360 \mathrm{~nm}$

\subsection{Validation model}

Validation tests (Table 10) were performed under the optimum condition to determine the adequacy of the model (Equation 4). According to reduced-linear model, the predicted result for browning intensity (2.52) obtained under the optimum conditions was close to the actual response observed. According to Montilha et al. (2017) relative error values in the range, $10-15 \%$ is acceptable in an optimization process. From Table 10 the error percentage for the model was less than $7 \%$ indicating that the response surface reduced linear model was adequate to predict the browning intensity of Maillard products of the bovine gelatine-xylose system.

\section{Conclusion}

Optimization using RSM with a central composite design is relevant to obtain the browning intensity of Maillard products of bovine gelatine-xylose model. Based on the validation tests, initial $\mathrm{pH}$ of 10.92 , reaction temperature of $140^{\circ} \mathrm{C}$ and heating time of 37.28 minutes were considered as the optimum condition for Maillard reaction of bovine gelatine-xylose with the browning intensity of 2.52 at the wavelength of $360 \mathrm{~nm}$. The linear model is adequate for the response with a coefficient of determination, $\mathrm{R}^{2}$ value of 0.8429 . It means that all parameters have shown a good fit with the experimental data at $95 \%$ confidence level.

\section{Acknowledgements}

This research was funded by the Indonesia Endowment Fund for Education (LPDP) via Beasiswa Pendidikan Indonesia (PRJ-133/LPDP.3/2017) and RIGS16-332-0496 (IIUM).

\section{References}

Ames, J. M. and Apriyantono, A. (1994). Comparison of the non-volatile ethyl acetate-extractable reaction products formed in a xylose-lysine model system heated with and without $\mathrm{pH}$ control. Food Chemistry, 50(3), 289-292. https:// doi.org/10.1016/0308-8146(94)90135-X

Burin, V.M., Marchand, S., De Revel, G. and Bordignon -Luiz, M.T. (2013). Development and validation of method for heterocyclic compounds in wine: Optimization of HS-SPME conditions applying a response surface methodology. Talanta, 117, 87-93. https://doi.org/10.1016/j.talanta.2013.08.037

Chen, X.-M. and Kitts, D.D. (2008). Antioxidant activity and chemical properties of crude and fractionated maillard reaction products derived from four sugaramino acid maillard reaction model systems. Annals of the New York Academy of Sciences, 1126(1), 220224. https://doi.org/10.1196/annals.1433.028

Gu, F., Abbas, S. and Zhang, X. (2009). Optimization of Maillard reaction products from casein - glucose using response surface methodology. LWT - Food Science and Technology, 42(8), 1374-1379. https:// doi.org/10.1016/j.lwt.2009.03.012

Hamizah, A., Hammed, A.M., Asiyanbi-H, T.T., Mirghani, M.E.S., Jaswir, I. and Fadzilah, N.H. (2017). Evaluation of catalytic effects of chymotrypsin and $\mathrm{Cu}^{2+}$ for development of UVspectroscopic method for gelatine-source differentiation. International Journal of Food Science, 2017, 1-5. https:// doi.org/10.1155/2017/2576394

Jaeger, H., Janositz, A. and Knorr, D. (2010). The Maillard reaction and its control during food processing. Pathologie Biologie, 58(3), 207-213. https://doi.org/10.1016/j.patbio.2009.09.016

Kwak, E.J. and Lim, S.I. (2004). The effect of sugar, amino acid, metal ion, and $\mathrm{NaCl}$ on model Maillard reaction under pH control. Amino Acids, 27(1), 8590. https://doi.org/10.1007/s00726-004-0067-7

Liu, Q., Niu, H., Zhao, J., Han, J. and Kong, B. (2016). Effect of the reactant ratio on the characteristics and antioxidant activities of maillard reaction products in 
a porcine plasma protein hydrolysate-galactose model system. International Journal of Food Properties, 19(1), 99-110. https:// doi.org/10.1080/10942912.2015.1017048

Martins, S., Martins, S.I.F.S. and Jongen, W.M.F. (2000). A review of Maillard reaction in food and implications to kinetic modeling. Trends in Food Science and Technology, 11(9-10), 364-373. https:// doi.org/10.1016/S0924-2244(01)00022-X

Montilha, M., Sbroggio, M.F., Figueiredo, V.R.G., Ida, E.I. and Kurozawa, L.E. (2017). Optimization of enzymatic protein hydrolysis conditions of okara with endopeptidase alcalase. International Food Research Journal, 24(3), 1067-1074.

Nursten, H. (2005). The Maillard Reaction. London, UK: The Royal Society of Chemistry.

Rizzi, G. (2011). Chemical structure of colored Maillard reaction products. Food Reviews International, 13 (1), 1-28. https:// doi.org/10.1080/87559129709541096

Tan, T.C., Alkarkhi, A.F.M. and Easa, A.M. (2012). Assessment of the ribose-induced Maillard reaction as a means of gelatine powder identification and quality control. Food Chemistry, 134(4), 2430-2436. https://doi.org/10.1016/j.foodchem.2012.04.049

Van Boekel, M.A.J.S. (2006). Formation of flavour compounds in the Maillard reaction. Biotechnology Advances, 24(2), 230-233. https://doi.org/10.1016/ j.biotechadv.2005.11.004

Wang, H.Y., Qian, H. and Yao, W.R. (2011). Melanoidins produced by the Maillard reaction: Structure and biological activity. Food Chemistry, 128(3), 573-584. https://doi.org/10.1016/ j.foodchem.2011.03.075

Zhang, K., Zhang, B., Chen, B. and Jing, L. (2016). Modeling and optimization of Newfoundland shrimp waste hydrolysis for microbial growth using response surface methodology and artificial neural network, Marine Pollution Bulletin, 109(1), 245-252. https://doi.org/10.1016/j.marpolbul.2016.05.075 